\title{
Docência universitária e letramento digital: desafios da formação de professores
}

\author{
University teaching and digital literacy: \\ challenges of teacher training \\ Docencia universitaria y alfabetización digital: \\ desafios de la formación de profesores \\ MARIA PAULINA DE ASSIS (Da \\ Elis Regina dA Costa (Db \\ Wender FALEIRO (DC
}

\section{Resumo}

As escolas têm cada vez mais utilizado as tecnologias digitais, sendo comum o uso de ambientes virtuais de aprendizagem (AVA) e de rede sociais nas universidades. Surge daí a necessidade do desenvolvimento de competências para o uso das tecnologias digitais na formação docente, tratadas, neste artigo, como letramento digital. Desse modo, este artigo teve como objetivo investigar o que tem sido pesquisado sobre letramento digital no âmbito da docência universitária em publicações em língua portuguesa. Durante o mês de fevereiro de 2020, analisamos publicações a respeito de letramento digital na formação de professores, por meio de uma revisão sistemática, utilizando o Google Acadêmico, com os seguintes critérios de inclusão: publicações no período de 2010 a 2019, revisados por pares, com o termo "letramento digital", ou "literacia digital" no título, que tratassem de

\footnotetext{
a Universidade Federal de Catalão (UFCAT), Catalão, GO, Brasil. Doutora em Educação, e-mail: paulina@ufg.br.

b Universidade Federal de Catalão (UFCAT), Catalão, GO, Brasil. Doutora em Educação, e-mail: elisufg@gmail.com.

' Universidade Federal de Catalão (UFCAT), Catalão, GO, Brasil. Doutor em Educação, e-mail: wender.faleiro@gmail.com.
} 
formação de professores. Selecionamos 22 artigos, nos quais o foco, as palavraschave, o problema de pesquisa e uma síntese dos principais resultados foram analisados. Os dados encontrados apontaram que os autores usam preferencialmente abordagens qualitativas, apresentam os desafios enfrentados por professores na aquisição de competências de letramento digital, mostrando alguns resultados com posições mais otimistas e outras mais céticas com relação a ações de capacitação docente. Dentre as soluções para os desafios, há sugestões para a formação dos professores, para o desenvolvimento das competências necessárias ao letramento digital. Embora esta possa ser uma solução de primeira escolha, não se pode descartar outras ações, como trabalho colaborativo entre professores e alunos, entre colegas docentes, com suporte de pesquisadores da academia.

Palavras-chave: Letramento digital. Docência universitária. Formação de professores.

\section{Abstract}

Schools have increasingly used digital technologies, with the use of virtual learning environments (VLE) and social networks in universities being common. Hence, the need to develop skills for the use of digital technologies in teacher training, which are treated in this paper as digital literacy. Thus, the objective of this paper was to investigate what has been researched on digital literacy in the context of university teaching in publications in the Portuguese language. During February 2020, we analyzed publications about digital literacy in teacher training through a systematic review, using Google Scholar, with the following inclusion criteria: publications from 2010 to 2019, peer-reviewed, with the term "digital literacy" in the title (in Portuguese the terms used were letramento digital or literacia digital), which dealt with teacher training. We selected 22 papers, in which the focus, keywords, research problem and a synthesis of the main results were analyzed. The data found showed that the authors preferentially use qualitative approaches, present the challenges faced by teachers in the acquisition of digital literacy skills, showing some results with more optimistic positions and others more skeptical regarding teacher training actions. Among the solutions to the challenges, there are suggestions for the training of teachers, for the development of the skills necessary for digital literacy. Although this may be a solution of first choice, other actions cannot be ruled out, such as collaborative work among teachers and students, fellow teachers, with the support of researchers from the academy.

Keywords: Digital literacy. University teaching. Teacher training.

\section{Resumen}

Las escuelas han utilizado cada vez más las tecnologías digitales, siendo común el uso de ambientes virtuales de aprendizaje (AVA) y de redes sociales en las universidades. Surge de ahí la necesidad del desarrollo de competencias para el uso de tecnologías 
digitales en la formación docente, tratadas en este artículo, como alfabetización digital. De ese modo, este artículo tuvo como objetivo investigar lo que ha sido pesquisado sobre alfabetización en el ámbito digital de la docencia universitaria en publicaciones en lengua portuguesa. Durante febrero de 2020, analizamos las publicaciones a respeto de la alfabetización digital en la formación docente, por medio de una revisión sistemática, utilizando el Google Académico, con los siguientes criterios de inclusión: publicaciones en el periodo de 2010 a 2019, revisadas por pares, con el término "alfabetización digital", en el título (en lengua portuguesa los términos utilizados fueron letramento digital o literacia digital), que traten de la formación de profesores. Seleccionamos 22 artículos, en los cuales el enfoque, las palabras clave, el problema de investigación y una síntesis de los principales resultados fueron analizados. Los datos encontrados señalaron que los autores utilizan preferentemente enfoques cualitativos, presentan los desafíos enfrentados por profesores en adquisición de competencias de alfabetización digital, mostrando algunos resultados con posiciones más optimistas y otras más escépticas con relación a las acciones de formación docente. Entre las soluciones para los desafíos, hay sugerencias para la formación de los profesores para el desarrollo de las competencias necesarias para la alfabetización digital. Aunque esta pueda ser una solución de primera elección, no se pueden descartar otras acciones, como trabajo colaborativo entre docentes y alumnos, entre compañeros docentes, con el apoyo de investigadores de la Academia.

Palabras clave: Alfabetización digital. Docencia universitaria. Formación docente.

\section{Introdução}

Tanto na educação formal quanto na informal, ${ }^{1}$ os ambientes de aprendizagem têm cada vez mais utilizado as tecnologias digitais. Mesmo nos cursos de formação de professores nos quais o ensino é total ou predominantemente presencial, professores e alunos devem utilizar seus computadores ou dispositivos digitais móveis, como tablets e celulares, seja para a gestão acadêmica, para a disponibilização de materiais didáticos, seja para variados objetivos de comunicação, como orientações, agendamento de encontros, avisos, dentre outros. $\mathrm{O}$ uso de ambientes

\footnotetext{
${ }^{1}$ Educação formal é aquela com intencionalidade, desenvolvida em instituições escolares, com propósitos de oferecer conhecimentos estruturados, necessitando de planejamento e de sistematização. Já a educação informal acontece no decorrer da vida dos indivíduos, ocorrendo em espaços familiares e outros fora da escola, normalmente por compartilhamento de experiências.
} 
virtuais de aprendizagem (AVA) é comum nas universidades e, além disso, tem sido frequente a utilização de redes sociais para comunicação entre alunos e professores.

Pesquisas recentes demonstram que o acesso às tecnologias digitais tem se ampliado nos últimos anos, também pelas camadas populares da sociedade, segundo o Comitê Gestor da Internet no Brasil (CGI.br, 2015; 2019), principalmente pela camada mais jovem da população. Isso indica que “[...] a Internet passou a ser elemento fundamental de socialização e ferramenta básica para aqueles que entram no mercado de trabalho" (CGI.br, 2019, p. 23). Essa informação reforça a presença das tecnologias digitais nas vidas das pessoas de todas as faixas etárias e, principalmente, de educadores e de docentes formadores de professores.

O conjunto de competências ${ }^{2}$ para o uso das tecnologias digitais tem sido chamado de letramento digital, literacia digital ou alfabetização digital. Uma pluralidade de termos que busca descrever um conjunto de habilidades necessárias ao manejo das tecnologias digitais para uso individual e coletivo, em distintos ambientes, mas essencialmente para professores, pois são eles os formadores das crianças, dos jovens e dos novos profissionais.

Este trabalho partiu, então, de uma inquietação que vem da sala de aula e de uma curiosidade epistemológica sobre o que a pesquisa científica em língua portuguesa aponta em termos de desafios do letramento digital na formação de professores. Ao considerarmos a importância do letramento digital no processo de ensino e de aprendizagem, tivemos como objetivo investigar o que tem sido estudado e pesquisado sobre letramento digital na docência universitária em publicações em língua portuguesa, em periódicos nacionais e internacionais.

Para atingir esse objetivo, pesquisamos artigos no Google Acadêmico. A busca dos artigos foi feita no mês de fevereiro de 2020 e utilizamos como critérios de inclusão trabalhos que tratam de temas educacionais escritos em língua portuguesa, a princípio com o termo exato "letramento digital", no título, e "formação", no título, ou no resumo, ou nas palavras-chave, publicados em periódicos avaliados por pares, disponível para download gratuito, durante o período compreendido entre 2010 e 2019.

\footnotetext{
${ }^{2} \mathrm{O}$ termo competência, neste artigo, refere-se ao conjunto de conhecimentos, habilidades e atitudes do professor no uso das tecnologias digitais e a apropriação destas quando há intenção de utilizá-las como suporte às ações de ensino e aprendizagem.
} 
Com a pesquisa em andamento, definimos buscar também trabalhos com os termos "literacia digital" e "alfabetização digital" por serem esses dois termos comumente utilizados em alguns trabalhos encontrados na fase de coleta de dados.

Utilizamos, inicialmente, o método de revisão sistemática e, em seguida, uma análise qualitativa dos dados. Os resultados mostraram um total de 22 artigos. De maneira resumida, há uma preferência para o uso do termo "letramento digital" sobre literacia e alfabetização digital, as revistas de preferência dos autores são da área de Letras e a análise das palavras-chave mostram temas relacionados às áreas de Letras, Educação e Tecnologia.

Considerando que a frequência do termo "letramento digital" é maior do que a dos outros dois termos (literacia e alfabetização digital) nas publicações pesquisadas, optamos por priorizá-lo neste trabalho. Dito isso, este artigo está organizado da seguinte forma: introdução sobre o tema, seguida de fundamentação teórica sobre letramento digital. Na sequência, a descrição do método de pesquisa, a análise e a discussão dos resultados, concluindo-se com as considerações finais, que focam nas implicações pedagógicas do letramento digital na formação docente universitária e seus desafios para o professor em formação e em serviço.

\section{Letramento digital}

Uma quantidade expressiva de inovações surge diariamente nas tecnologias digitais. Assim, o amplo uso de tecnologias móveis para uso pessoal modifica consideravelmente os diversos setores da sociedade. Nos dias atuais, os estudantes como futuros profissionais - necessitam de direção e de educação para serem bemsucedidos na utilização do mundo digital em que nasceram (THOMPSON, 2016).

Assim sendo, cresce a importância do estudo das tecnologias contemporâneas na educação. Ao usarem essas tecnologias, os professores não podem negligenciar as experiências dos alunos fora da sala de aula, "[...] eles precisam trazer para os alunos formas de entendê-las" (BUCKINGHAM, 2006, p. 264, tradução nossa). A isso o autor chama de "letramento digital". Assim como Buckingham (2006), Ata e Yildirim (2019) afirmam que, atualmente, o letramento digital tem um papel essencial do indivíduo como cidadão em uma sociedade tecnológica. Para esses autores, é essencial 
atuar na capacitação em letramento digital na educação e verificar "[...] até que ponto os professores têm conhecimento suficiente em tecnologias digitais, suas crenças sobre o uso delas nas práticas instrucionais relevantes em suas salas de aula" (ATA; YILDIRIM, 2019, p. 2, tradução nossa). Daí ressaltamos a importância de educar indivíduos críticos, conscientes das formas e dos usos das tecnologias digitais da informação e comunicação (TDIC), sendo, para isso, imprescindível o desenvolvimento de competências de letramento digital.

O termo "letramento digital" tem sido usado por autores brasileiros, enquanto pesquisadores portugueses usam literacia digital (ALVES; SILVA, 2015; OLIVEIRA; GIACOMAZZO, 2017), e, ainda, alguns autores optam por "alfabetização digital” (COLELLO, 2016; PEREIRA, 2016). Considerando que o termo "letramento digital" é o mais usado nas publicações pesquisadas, optamos por enfatizá-lo neste trabalho.

Segundo a Organização das Nações Unidas para a Educação, a Ciência e a Cultura (UNESCO), o termo letramento digital

[...] compreende um conjunto de habilidades básicas que incluem o uso e a produção de mídia digital, processamento e recuperação de informações, participação em redes sociais para criação e compartilhamento de conhecimento e uma ampla variedade de habilidades profissionais em computação (UNESCO, 2011, p. 1, tradução nossa).

O termo digital literacy (letramento digital) foi utilizado pela primeira vez por Gilster (1997) no início da disseminação da Internet. O autor argumenta que o letramento digital não está relacionado às habilidades técnicas, mas, sim, ao pensamento crítico e à avaliação de informação, sendo uma pessoa letrada digital aquela que, além de habilidade, teria prontidão, vontade e inclinação para utilizar as tecnologias digitais. Segundo o pesquisador, o letramento digital está relacionado ao domínio de ideias, não ao pressionamento de teclas (GILSTER, 1997). Bawden (2008) distingue o seu conceito de outros que são mais limitados a um conjunto de competências. Segundo Eshet-Alkalai (2004), o letramento digital é muito mais do que as habilidades para utilizar um dispositivo, pois inclui uma grande e complexa variedade de habilidades tais como: cognitivas, motoras, sociológicas e emocionais "[...] que o usuário precisa para poder operar efetivamente em ambientes digitais" (ESHET-ALKALAI, 2004, p. 93, tradução nossa), 
Essas formulações conceituais assemelham-se à de Gilster (1997), constantemente citada na literatura internacional, por possuir uma ideia mais ampla de letramento digital (BAWDEN, 2008). Lankshear e Knobel (2006) enfatizam a necessidade de professores aprenderem as habilidades, utilizar a Internet de maneira apropriada e crítica e ensinarem seus alunos. Outros autores também criticam as definições de letramento digital como competência que não leva em conta as diversas relações sociais, em que a apropriação das tecnologias como um tipo de linguagem se estabelece, se modifica ou desaparece, restringindo, portanto, o conceito (SOARES, 2002; BUCKINGHAM, 2006; BUZATO, 2010. Por isso, a importância de investigações nas áreas de Educação, Linguagens e Tecnologia, dentre outras, como poderá ser visto nos trabalhos pesquisados neste artigo.

Por essa breve exposição, podemos perceber que o termo "letramento digital" historicamente tem sido multifacetado e plural, abrangendo questões desde as mais técnicas, com preocupações mais funcionais relativas às ciências tecnológicas, passando por questões psicológicas e sociais. Todas essas e outras mais não podem escapar ao olhar atento do docente universitário, que forma o professor, responsável, em primeira instância, pela capacitação das crianças, dos jovens e dos adultos, para um letramento digital que, mais do que técnico, seja essencialmente humano.

\section{Método de pesquisa}

Ao considerarmos o objetivo deste trabalho, acreditamos que a melhor opção de método de pesquisa seria o da revisão sistemática. Esta busca analisar e sintetizar a literatura existente em determinado assunto ou tópico (GOUGH, 2007) e, também, responder a uma pergunta explícita sobre determinado tema por meio do estudo da literatura existente e de métodos transparentes que permitam realizar uma pesquisa detalhada e completa, de modo a possibilitar a análise crítica de estudos individuais e ter como meta revelar o que se sabe e o que não se sabe sobre determinado assunto (BRINER; DENYER, 2012).

O termo "sistemática" significa que os autores seguem um protocolo de pesquisa que pode ou não ser padrão, e comunicam o que foi feito, os percursos metodológicos utilizados, explicitando procedimentos utilizados na pesquisa 
(GOUGH, 2007; BRINER; DENYER, 2012; KITCHENHAM, 2004; GRANT; BOOTH, 2009). Ao planejar uma revisão sistemática, é necessário elaborar um protocolo de pesquisa (KITCHENHAM, 2004; GOUGH, 2007; BRINER; DENYER, 2012; RAMOS; FARIA, 2012).

A pesquisa científica mostra que grande parte dos trabalhos de revisão sistemática é realizada na área da medicina (GOUGH; THOMAS; OLIVER, 2012; RAMOS; FARIA, 2012; SAUR-AMARAL, 2011). Entretanto, quando há necessidade de utilizar essa metodologia em outras áreas, não se pode simplesmente copiar os princípios e os métodos dos estudos realizados no campo da medicina e outras áreas da saúde. Desse modo, Briner e Denyer (2012) aconselham que os métodos sejam adaptados para adequar a questão que a pesquisa está tratando e também as suas premissas (subjacentes) ou pressuposições.

Vários autores propõem um conjunto de etapas a serem seguidas em um protocolo de revisão sistemática (SAUR-AMARAL, 2011; TRANFIELD; MOUCHEL, 2002; GOUGH; THOMAS; OLIVER, 2012; RAMOS; FARIA, 2012), semelhantes ao de Briner e Denyer (2012, p. 115), os quais propõem cinco passos principais, adaptados no protocolo como mostra a Figura 1 a seguir.

\section{Figura 1 - Passos da revisão sistemática}

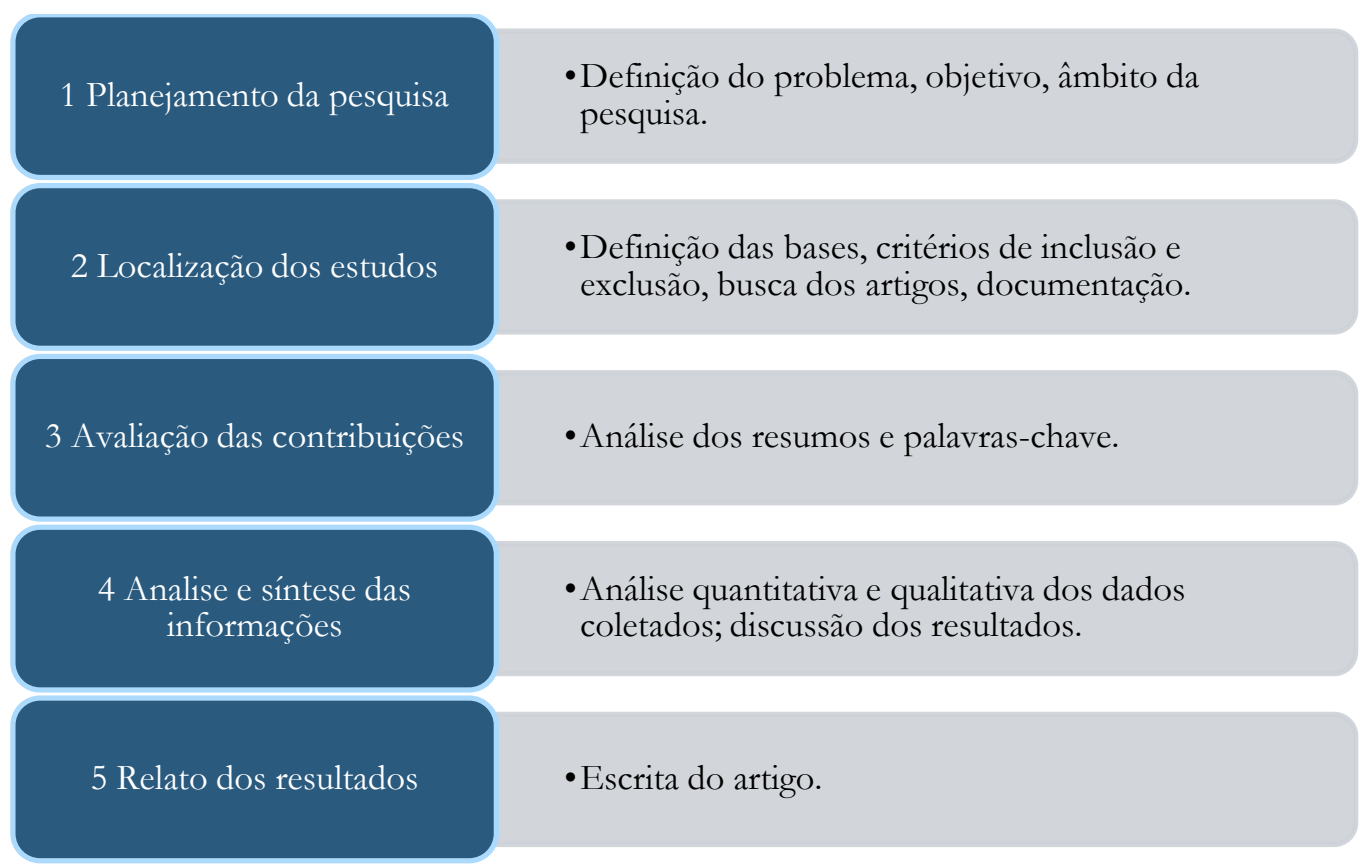

Fonte: Adaptado de Briner e Denyer (2012, p. 115). 
Além dos passos descritos, esses autores propõem cinco princípios essenciais para as revisões sistemáticas, as quais devem ser: sistemáticas e organizadas; transparentes e explícitas; replicáveis e atualizáveis; ter resultados sintetizados e sumarizados.

\section{Escolha da fonte de dados}

Após definirmos o objetivo e o método de pesquisa, determinamos a base de dados em que faríamos a coleta dos dados. Optamos pelo Google Acadêmico, por ser uma fonte de publicações científicas, além de possuir uma massa de dados considerável e indexar inúmeros periódicos científicos, repositórios de dados universitários e editores nacionais e internacionais. Uma questão crítica sobre essa base de dados é que ela não oferece filtros para buscas, como é o caso de bases acadêmicas já consolidadas, como as que encontramos no Portal de Periódicos da Coordenação de Aperfeiçoamento de Pessoal de Nível Superior (Capes). A forma de lidarmos com as dificuldades na coleta de dados no Google Acadêmico foi pautada na decisão de buscarmos artigos com os termos de pesquisa no título, o que poderia, a princípio, limitar os resultados da busca, mas, em contrapartida, nos possibilitou selecionar artigos que realmente tratavam do tema de investigação científica.

\section{Critérios de seleção dos dados}

Realizamos a coleta de dados em fevereiro de 2020 utilizando os seguintes critérios para inclusão:

- Artigos em língua portuguesa, de autores brasileiros, portugueses ou de outras nacionalidades:

- com um dos termos letramento digital, literacia digital e alfabetização digital + formação no título;

- que tratassem de docência universitária;

○ publicados no período de 2010 a 2019;

○ publicados por periódicos revisados por pares, nacionais ou internacionais;

○ disponíveis para download gratuito. 
Os critérios para exclusão foram:

- artigos que tinham variações nos termos, tais como: letramento científico digital, letramento literário digital, ou letramento midiático digital;

- artigos apresentados em congressos, seminários, etc.;

- editorias;

- resenhas;

- capítulos de livros;

- teses, dissertações, memoriais, trabalhos de conclusão de cursos, relatórios de pesquisa que não fossem em formato de artigo;

- trabalhos apresentados em congressos;

- documentos oficiais, livros;

- artigos de autores brasileiros (e portugueses) publicados em revistas do exterior em outra língua que não o Português;

- $\quad$ artigos escritos por alunos de graduação, sem a coautoria de professores.

\section{Etapas da coleta}

Inicialmente, para a busca, utilizamos o recurso de Pesquisa avançada do Google Acadêmico, optando pelo termo "letramento digital" (entre aspas) no título do artigo para assegurar que o termo estivesse exato e não com variações, e, também, incluímos o termo "formação" dentro do campo com, no mínimo, uma das palavras. Definido o período (2010-2019), foram excluídos documentos de patentes e de citações, recursos oferecidos por essa base de dados.

Encontramos aproximadamente 80 trabalhos sobre letramento digital e formação. Na sequência, buscamos os trabalhos sobre literacia digital e alfabetização digital, encontrando 13 e dois registros, respectivamente. A seguir, a Figura 1 mostra a página do Google Acadêmico quando buscamos o termo letramento digital. 
Figura 2 - Ilustração de busca no Google Acadêmico

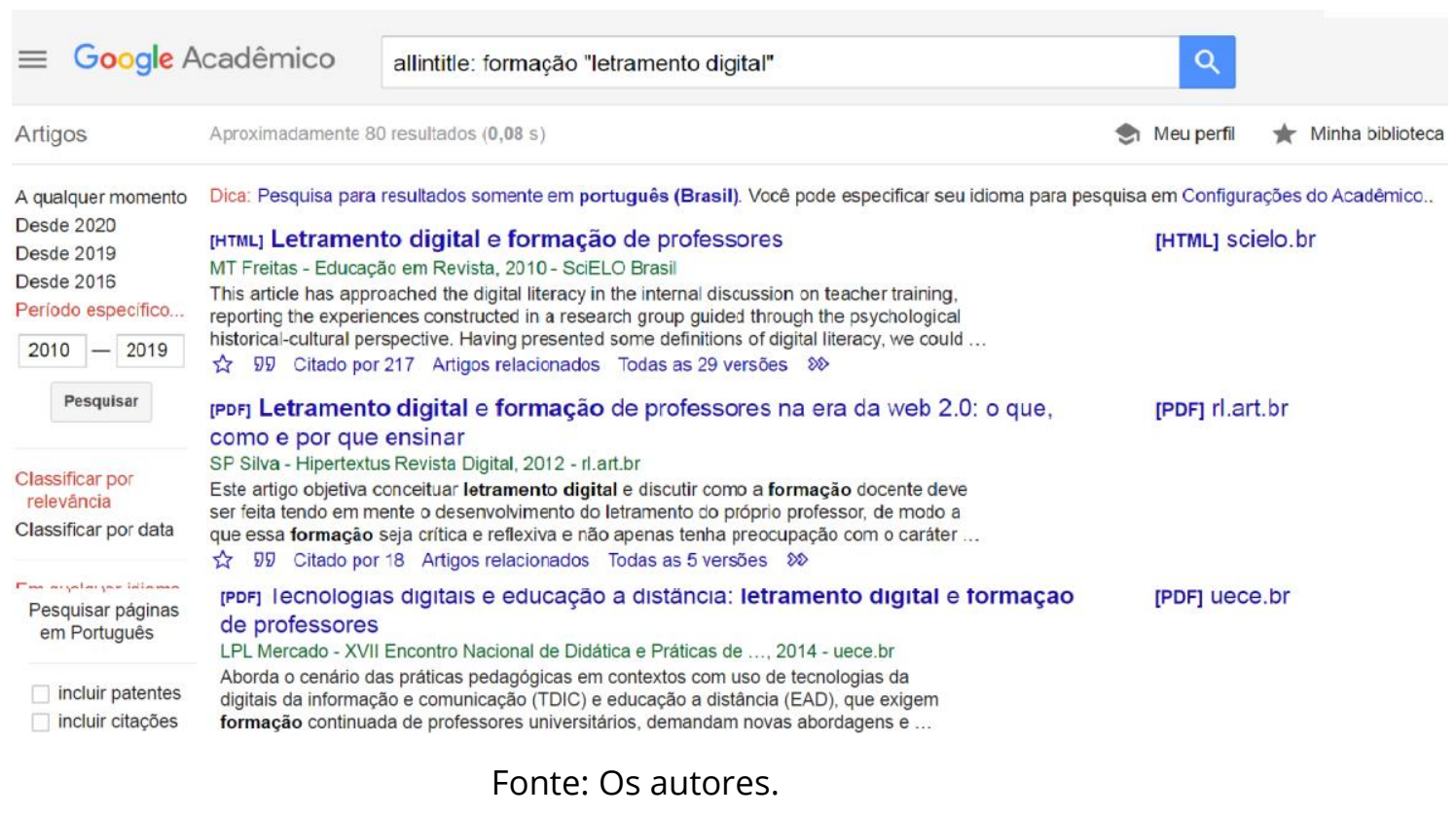

Baixamos cada trabalho e procedemos à análise dos seguintes itens: se o texto era artigo ou não; se não, era já descartado; se sim, verificávamos a acurácia da referência, certificávamos a sua correspondência às informações sobre o título e ano de publicação do trabalho, se havia sido apresentado em congresso, e a ordem dos nomes dos autores. Em seguida, abríamos o site da revista para verificar se era avaliada por pares. Na sequência, salvamos os artigos que atenderam aos critérios de inclusão e exclusão na Minha biblioteca do Google Acadêmico, com o marcador "DOCÊNCIA UNIVERSITÁRIA".

Ao final, selecionamos 22 artigos sobre letramento digital, um sobre literacia digital, mas nenhum sobre alfabetização digital. Os resultados referiam-se a publicações de periódicos que atendiam ao critério de terem avaliação por pares, dentro do período de 2010 a 2019. Em seguida, procedemos à documentação dos artigos.

\section{Documentação dos artigos}

Todos os artigos foram salvos em PDF em uma pasta do Windows. Esses documentos foram também salvos no Google Drive para compartilhamento entre as autoras durante a pesquisa e escrita do artigo e, também, para uso futuro. Elaborou- 
se uma tabela com os seguintes dados: o foco do estudo, os conceitos-chave utilizados, o problema de pesquisa, o método e uma síntese dos achados.

\section{Resultados e discussão}

Dentro dos critérios adotados na pesquisa, selecionamos 22 trabalhos, sendo 21 sobre letramento digital e um sobre literacia digital, no período de 2010 a 2019. Classificamos em itens, seguindo os aspectos:

- foco do estudo;

- conceitos-chave;

- problema de pesquisa e síntese dos achados.

No decorrer do artigo, vamos nos referir a esses itens, apresentando discussões sobre os dados da pesquisa.

\section{Distribuição dos trabalhos por ano e categoria}

Preliminarmente, apresentamos uma visão geral dos artigos por ano de publicação e categorias nas quais os agrupamos: Línguas, Educação e Tecnologia, como ilustramos no Gráfico 1 a seguir.

Gráfico 1 - Total de artigos por ano e categoria

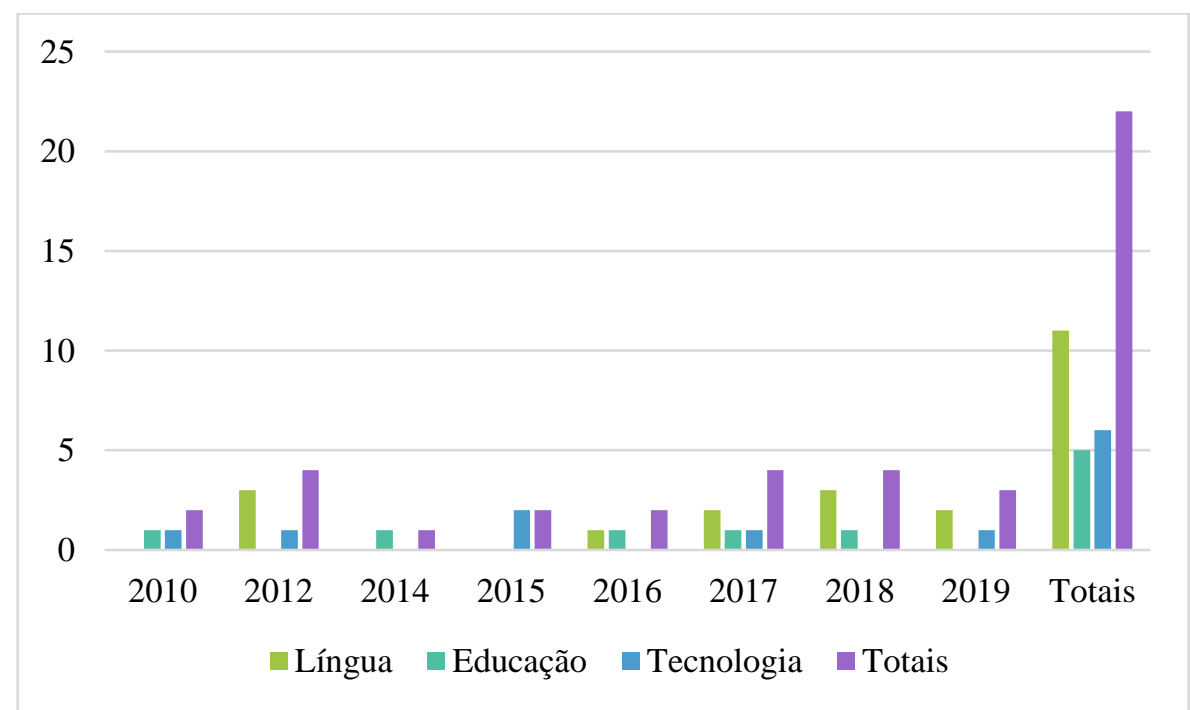

Fonte: Os autores. 
Como podemos observar, os trabalhos são distribuídos ao longo dos anos sem muitas diferenças no total de publicações por ano. Não encontramos trabalhos dentro dos critérios adotados para os anos de 2011 e 2013. O ano com menor número de trabalhos foi o de 2014, tendo os anos de 2012, 2017 e 2018 quatro trabalhos cada um. Acreditamos que teremos mais publicações referentes a 2019, visto estarmos ainda no início de 2020, sendo possível que haja novas indexações no decorrer do ano.

\section{Foco das pesquisas}

Apresentamos, nesta subseção, o foco dos 22 trabalhos selecionados, utilizando o agrupamento nas três categorias — Línguas, Educação e Tecnologia. Analisamos os trabalhos e identificamos em cada um deles o foco da pesquisa, sendo este sempre a relação do letramento digital com um contexto educacional, como, por exemplo, um curso, uma área de ensino, ou um ambiente virtual de aprendizagem. Em geral, os textos tratam de desafios relacionados ao letramento digital dentro de determinado contexto educacional. O Gráfico 2 a seguir ilustra os achados sobre os focos de pesquisa identificados nos artigos.

Gráfico 2 - Focos das pesquisas

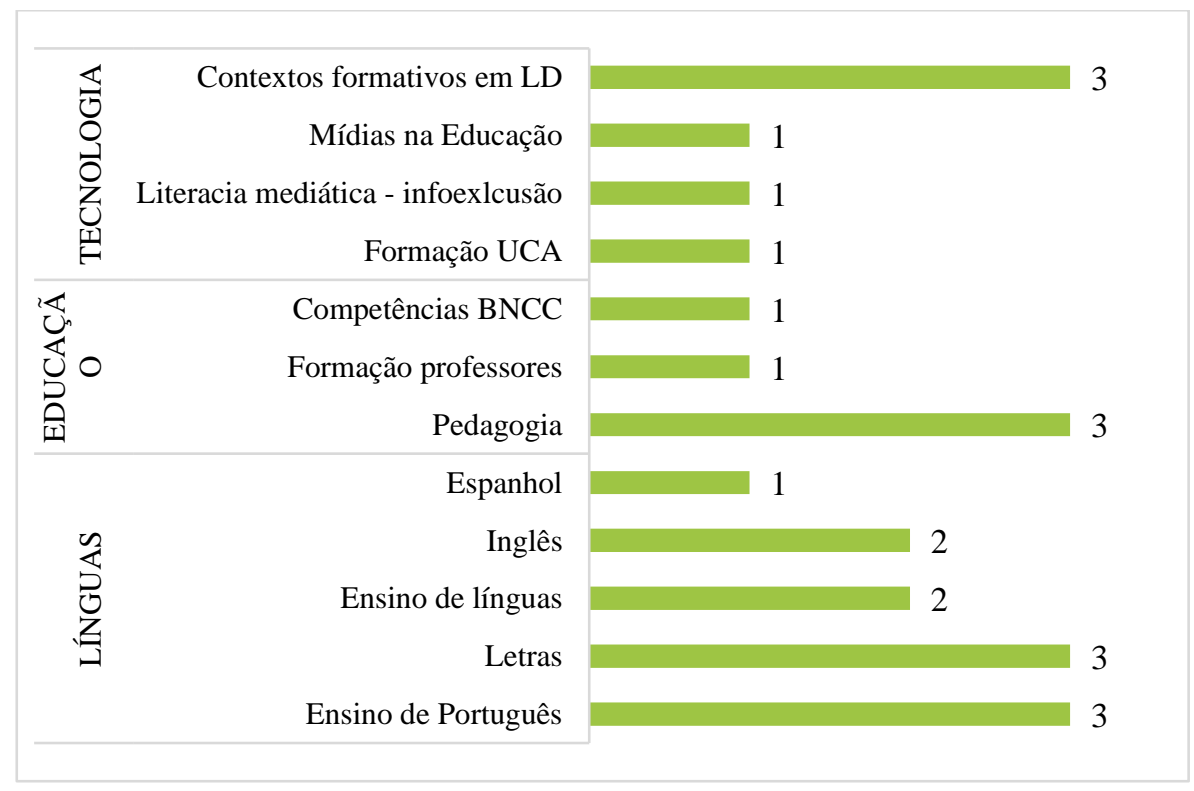

Fonte: Os autores.

Legenda: LD - Letramento Digital; UCA - Projeto Um Computador por Aluno; BNCC Base Nacional Comum Curricular. 
$\mathrm{Na}$ categoria Linguas, foram encontrados três artigos que pesquisaram o letramento digital em cursos de Português; três em cursos de Letras; dois em ensino de línguas; dois em cursos de Inglês; um em Espanhol - totalizando 11 trabalhos. Agrupados na categoria Educação, foram cinco trabalhos, sendo encontradas três pesquisas em cursos de Pedagogia; uma em formação de professores; e uma pesquisa relacionada às novas competências requeridas aos profissionais, tendo como parâmetro a nova Base Nacional Comum Curricular Brasileira (BNCC) e a chegada do Letramento Digital na formação docente. Na categoria Tecnologia, tivemos um trabalho sobre capacitação de professores no âmbito do Projeto Um Computador por Aluno (UCA); um sobre literacia mediática e infoexclusão; e três para pesquisas em contextos formativos em Letramento Digital (LD) - totalizando seis trabalhos.

De forma resumida, observamos, por um lado, uma ligeira tendência para a pesquisa em letramento digital nas áreas de formação de professores nos cursos de ensino de línguas, que representaram a metade dos focos dos trabalhos selecionados. Por outro lado, há um equilíbrio entre os focos das pesquisas dentro das categorias Educação e Tecnologia, o que reflete a associação do letramento digital a preocupações com o ensino e a aprendizagem e, essencialmente, aos aspectos tecnológicos dos ambientes educacionais utilizados na formação de professores.

\section{Análise das palavras-chave}

Para a análise das palavras-chave, anotamos todas as utilizadas nos trabalhos. As palavras-chave apresentam coerência com os temas pesquisados, de modo a apontar para as questões dos focos das pesquisas: letramento digital, com 20 ocorrências; professores, com 17; e formação de professores, com 12. O termo tecnologia/s, com oito ocorrências, também é significativo, considerando-se que, ao falar-se em letramento digital, os autores normalmente reportam-se ao advento das tecnologias digitais, sua entrada nas escolas e a necessidade de apropriação dessas tecnologias pelos professores. Os demais termos, educação, docente/s, Português e formação continuada, com menos de cinco ocorrências, estão, de certa forma, relacionados à formação de professores; dessa maneira, estão em conformidade com os demais, mostrando harmonia no conjunto. 
Importante ressaltarmos a baixa frequência da palavra-chave Educação, o que poderia, talvez, ser explicada pelo fato de que a maioria dos trabalhos selecionados tem sido nas áreas de línguas. Entretanto, isso chama atenção, pois o letramento digital também deveria ser tema de ensino e de pesquisa de outras áreas, tais como: Educação, Psicologia, Comunicação, Ciências Sociais, Ciências da Computação, dentre outras.

\section{Problemas de pesquisa, principais achados e argumentos}

Analisamos os problemas de pesquisa juntamente aos achados, em busca de encontrar associações entre eles, acreditando que deveria haver respostas para as questões levantadas pelos autores das pesquisas. Não conseguimos identificar o problema de todos os trabalhos, e, em alguns, não encontramos relações diretas entre o problema e os achados. Entretanto, dada a riqueza de propostas relativas aos desafios do letramento digital na docência universitária, essencialmente no campo das licenciaturas, consideramos todos os trabalhos selecionados para a análise. Assim, nesses casos, propusemos analisar o argumento do/s autor/es e suas considerações a respeito. Classificamos os 22 trabalhos nas categorias Línguas, Educação e Tecnologia, seguindo a mesma orientação da análise do foco, como tratado anteriormente. Assim, tivemos, na categoria Línguas, três artigos sobre cursos de Letras, dois sobre ensino de línguas, dois sobre ensino de Inglês e um sobre ensino de Espanhol. Na categoria Educação, tivemos três artigos sobre curso de Pedagogia, um sobre formação de professores e um sobre as competências da BNCC. Em Tecnologia, tivemos três sobre contextos formativos em LD, um sobre formação no âmbito do Projeto UCA e um sobre o curso Mídias na Educação. Assim sendo, a seguir, apresentamos as discussões sobre os problemas e os achados dos artigos em cada uma dessas categorias.

\section{Artigos classificados na categoria Línguas}

Na categoria Línguas, classificamos 11 trabalhos, sendo os três primeiros sobre o ensino de Português. A narrativa autobiográfica feita por Silva Júnior (2017) fala sobre os desafios do ensino de Português no Brasil. O autor destacou a importância 
da "[....] formação do professor de português tanto pela concepção de ensinoaprendizagem considerado na prática docente, até a qualificação profissional que o docente necessita para se emancipar no trabalho e em toda a relação que a educação abrange" (SILVA JÚNIOR, 2017, p. 341). O autor concluiu que a aquisição do letramento digital (pela professora que foi sujeito de sua pesquisa) “[...] se emprega em pontos como a formação docente e o investimento governamental em educação e tecnologia" (SILVA JÚNIOR, 2017, p. 340).

Francisco, Ferreira e Goulart (2019, p. 109) tratam da “"...] formação inicial e continuada de professores de língua portuguesa no que tange ao uso das tecnologias digitais de comunicação como estratégia para reelaboração e reconfiguração de suas práticas pedagógicas”. Os autores argumentam que as

[...] transformações tecnológicas e digitais que vêm ocorrendo na sociedade e que, consequentemente, atingem o interior das salas de aula têm interferido em nossas práticas pedagógicas e nas relações entre o ensinar e o aprender, exigindo de nós, professores, uma busca constante por formação (FRANCISCO; FERREIRA; GOULART, 2019, p. 109).

Como conclusão do trabalho, os autores ressaltam que:

Se falta conhecimento aos professores de língua portuguesa para lidar com as novas configurações de linguagem nas mídias digitais, torna-se urgente a busca de formação inicial e continuada, dado que o número de textos veiculados nas mídias digitais carregam características que exigem dos leitores o saber associar a linguagem verbal e a não verbal, além da compreensão do porquê do formato do texto, das cores utilizadas, do tipo linguagem utilizada, etc. (FRANCISCO; FERREIRA; GOULART, 2019, p. 118).

Landgraf-Valerio (2012, p. 1) analisou um “[...] Blog como estratégia pedagógica no processo de formação de professores de Língua Portuguesa”. A autora argumenta que

[...] a crescente inserção da tecnologia de informação e comunicação (TIC) em todas as esferas sociais tem alterado o cotidiano da educação básica no Brasil, uma vez que as necessidades dos alunos, jovens leitores inseridos em práticas digitais, têm exigido essa mudança de postura educacional (LANDGRAF-VALERIO, 2012, p. 1).

Os resultados de sua pesquisa esclarecem que a atualização "[...] dos Profissionais da Educação de Mato Grosso tem contribuído para a formação continuada e para o letramento digital dos professores de Língua Portuguesa da rede estadual” (LANDGRAF-VALERIO, 2012, p. 1) daquele Estado. 
Sobre o ensino em cursos de Letras, encontramos três trabalhos. Silva e Reis (2017) fizeram uma análise descritiva sobre a formação inicial de professores nas licenciaturas e a "[...] construção de práticas de letramento digital na formação de professores" (SILVA; REIS, 2017, p. 98), tomando como ponto de partida “[...] contribuições dos novos estudos do letramento, focalizando principalmente a apropriação do digital em ambientes de ensino" (SILVA; REIS, 2017, p. 97). Os autores trouxeram como resultado a "[...] demanda por inovação na formação inicial de professores nas licenciaturas, o que é motivado pelo diálogo mais estreito entre a universidade e as escolas de ensino básico, desencadeado nas referidas disciplinas" (SILVA; REIS, 2017, p. 116).

Nery, Costa e Souza (2018) abordaram, em uma discussão bibliográfica, o desafio do letramento na relação docente-discente. $O$ estudo concluiu que há necessidade da formação continuada do professor na área digital para efetivar o processo de aprendizagem, devendo a metodologia envolver recursos tecnológicos.

Marzari e Leffa (2013) utilizaram questionário e a análise crítica do discurso para pesquisar "[...] o papel da tecnologia no ensino de línguas e suas implicações para a prática docente” (MARZARI; LEFFA, 2013, p. 1). Os autores argumentaram que “[...] na era tecnológica, esse desafio (do letramento) ganha ainda mais força, uma vez que parece não haver tempo suficiente, principalmente por parte de professores, para aprenderem a lidar com tanta inovação de uma só vez" (MARZARI; LEFFA, 2013, p. 3). A análise dos autores revelou que

[...] a presença da tecnologia nos cursos de formação de professores de Letras restringe-se, na maioria das vezes, a disciplinas eletivas e atividades extracurriculares. Como consequência, esses professores não se sentem efetivamente preparados para atuar no atual contexto sócio-histórico, profundamente marcado pela presença das TIC. (MARZARI; LEFFA, 2013, p. 1).

Em uma pesquisa etnográfica, Bedran (2016) focou no processo de formação do professor de línguas, o qual deve ser desenvolvido

[...] a partir de uma perspectiva situada, que contemple as práticas e os eventos de letramento dos quais os alunos participam em situações extra-ambiente escolar e as ferramentas tecnológicas que possibilitem a realização e/ou sejam pertinentes para o desenvolvimento de novas práticas de letramento (BEDRAN, 2016, p. 226). 
A autora relatou que os dados de sua pesquisa “[...] evidenciaram que o sucesso da atividade não está relacionado diretamente à tecnologia apropriada, mas ao engajamento dos participantes na tarefa solicitada, que é influenciado e delineado por recursos tecnológicos, metodológicos e fatores contextuais" (BEDRAN, 2016, p. 242).

Outra pesquisa no ensino de línguas foi realizada por Cabral e Mickalski (2018), que teve como foco "[...] trazer as perspectivas de professores de línguas, atuantes na sala de aula, acerca do letramento digital" (CABRAL; MICKALSKI, 2018, p. 472). Por meio de entrevistas com professores de línguas: português, inglês e espanhol, as autoras revelaram que há um “[...] desconforto e a sensação de não domínio dos artefatos tecnológicos dos professores, as dúvidas que ainda permanecem em como se utilizar esta tecnologia toda" (CABRAL; MICKALSKI, 2018, p. 477) e que os entrevistados “[...] compreendem o letramento digital como o lúdico no ensino" (CABRAL; MICKALSKI, 2018, p. 475).

Sobre o ensino de Inglês, Oliveira e Mello-Paiva (2019) fizeram uma pesquisa etnográfica com um grupo de professores de inglês participantes de um curso de formação continuada.

O curso foi implementado como parte da Rede Nacional de Formação Continuada de Professores/as da Educação Básica do Ministério da Educação e Cultura (MEC) cuja meta é a implementação de políticas regionais que visem a formação continuada de professores de inglês da educação básica pública (OLIVEIRA; MELLOPAIVA, 2019, p. 107).

Os autores relataram que

[...] as experiências de letramento digital desse grupo aconteceram de forma natural, não pré-estabelecida, frequente, via input e output e intensamente colaborativas. Percebeu-se também que a característica inovadora das aulas executadas via instrumentos tecnológicos digitais [provocou] mudança de hábitos nesses professores em níveis tecnológico e organizacional (OLIVEIRA; MELLO-PAIVA, 2019, p. 105).

Santos e Cichelero (2012) analisaram dados gerados por fóruns de um curso de formação continuada de docentes de língua inglesa. Segundo os autores,

[...] muitas são as inquietações dos docentes acerca de como podem proporcionar um ensino que possibilite a partilha de conhecimentos significativos, desperte 0 desejo pelo aprendizado da leitura e escrita, e de temas que a escola privilegia e da qual, efetivamente, os alunos participem do processo de ensinar e aprender. (SANTOS; CICHELERO, 2012, p. 198). 
Os autores apontaram que

[...] é possível dizer que os concluintes compreenderam o papel dessa ferramenta e a caracterizaram como aliada e necessária ao seu desenvolvimento profissional, e que esse ambiente já se tornou familiar, além de outros ambientes virtuais, pois também houve momentos de interação do curso via e-mail (SANTOS; CICHELERO, 2012, p. 218).

Machado, Aragão e Lopes (2019) efetuaram uma análise documental de caráter qualitativo, em um curso de Licenciatura em Letras - Espanhol na modalidade a distância. Os autores questionaram:

[...] onde desenvolver esses novos letramentos exigidos pela sociedade atual e do futuro? A resposta mais evidente seria: na escola, no entanto o que percebemos é que a escola está ainda longe de ser essa agência de LD, seja por não possuir os recursos estruturais para isso - laboratórios de informática, conexão com a internet, para dizer o mínimo - ou por não possuir professores capacitados para promover e desenvolver esses letramentos. (MACHADO; ARAGÃO; LOPES, 2019, p. 52).

Os resultados apontam uma reduzida ou nula abordagem que contemple uma formação que capacite os futuros professores para o trabalho de fomento do letramento digital em sua prática docente.

\section{Artigos classificados na categoria Educação}

Três trabalhos pesquisaram o letramento digital em cursos de Pedagogia. Barbeta, Oliveira e Santos (2017) fizeram uma pesquisa exploratória com o intuito de "[...] compreender de que maneira as redes sociais se configuram como instrumentos para prática de letramento, e, após, verificar a necessidade de formação de professores nesse assunto" (BARBETA; OLIVEIRA; SANTOS, 2017, p. 38). Segundo os autores, os dados demonstram “[...] uma superficial compreensão em relação ao letramento digital e, ainda, a necessidade de formação de professores neste tema" (BARBETA; OLIVEIRA; SANTOS, 2017, p. 38).

Os outros dois trabalhos dessa categoria pesquisaram cursos de Pedagogia a distância. Gomes (2016) fez uma observação participante em encontros presenciais do curso e aplicou questionários e entrevistas. O autor teve como problema de pesquisa a importância de considerar-se que "[...] as tecnologias mudam o cenário dos ambientes de aprendizagem para os cursos oferecidos nesta modalidade" (GOMES, 
2016, p. 580), o que traz uma “[...] preocupação formal quanto às condições de formação do pedagogo" (GOMES, 2016, p. 580). Os resultados desse trabalho destacam " [...] os impactos provocados pelo uso das tecnologias digitais na formação inicial e, além disso, como essas alunas pensam as tecnologias digitais no ambiente escolar e que possibilidades veem para o seu uso na prática docente” (GOMES, 2016, p. 579).

No terceiro trabalho, nesta categoria, Medeiros e Nascimento (2014) aplicaram um questionário on-line e observação virtual, tendo como problema a " [...] formação de professores e a utilização da internet como ambiente de aprendizagem, visando compreender o processo de apropriação das tecnologias digitais por esse público" (MEDEIROS; NASCIMENTO, 2014, p. 74). Os resultados demonstraram que "[...] o texto e o discurso produzidos por esses indivíduos nesse ambiente modificam-se ao longo do tempo, influenciados que são pelas relações que os sujeitos estabelecem entre si, com a própria tecnologia e com o meio acadêmico" (MEDEIROS; NASCIMENTO, 2014, p. 74).

O artigo de Freitas (2010, p. 325) aborda “[...] o letramento digital no interior da discussão sobre a formação de professores dentro de um grupo de pesquisa”. A pesquisadora argumenta que “[...] a inserção do computador-internet no processo pedagógico acontece, principalmente, a partir de trabalhos realizados via ambientes virtuais de aprendizagem (AVA), [...] atividades essas que passam, necessariamente, pelo letramento digital” (FREITAS, 2010, p. 337), o que torna “[...] relevante e urgente uma discussão do letramento digital no trabalho com professores” (FREITAS, 2010, p. 337). A autora reporta “[...] a existência, na vida do grupo pesquisado, de práticas diferenciadas de leitura e escrita, em interação com diversos instrumentos culturais da contemporaneidade, destacando-se aí o uso do computador e da internet" (FREITAS, 2010, p. 336).

Oliveira e Souza (2018) fizeram um levantamento bibliográfico para discutir

[...] as novas competências profissionais enquanto ensino e aprendizagem, tendo como parâmetro a nova BNCC e a chegada do Letramento Digital na formação docente num cenário [...] de desafios [...] pelo confronto com as novas práticas de leitura e escrita propiciadas pelos usos dos computadores, recursos digitais e da internet (OLIVEIRA; SOUZA 2018, p. 133). 
Segundo os autores, “[...] o lugar do docente continua sendo insubstituível como mediador e problematizador do conhecimento, por isso é relevante e urgente a discussão do letramento digital do docente" (OLIVEIRA; SOUZA 2018, p. 133). A pesquisa traz como resultado indicações sobre a importância da formação continuada, tanto para professores atuantes no ensino há mais tempo, quanto aqueles formados recentemente, com destaque para o letramento digital como inovação educativa.

\section{Artigos classificados na categoria Tecnologia}

Alves e Silva (2015), com foco de pesquisa na "Literacia Mediática e Inclusão Sociodigital", apresentam um estudo de caso de curso mediado por tecnologias digitais, no qual investigaram "[...] os impactos dos cursos de formação online de professores sobre as suas habilidades e competências para o uso das tecnologias digitais no seu cotidiano e práticas pedagógicas” (ALVES; SILVA, 2015, p. 44). Segundo os autores, os dados "[...] apontam o uso das tecnologias nas práticas pedagógicas limitado na sala de aula. Criar apresentações em slides e projetar aos alunos foi a atividade mais frequente [...]" (ALVES; SILVA, 2015, p. 46).

Flores (2013) focou sua pesquisa no âmbito do projeto UCA, com um estudo de caso, no qual buscou “[...] compreender o desenvolvimento de práticas de letramento digital” (FLORES, 2013, p. 9) e constatou como resultado “[...] um nível superficial de ações de letramento digital e uma influência do modelo de educação centrado na transmissão de informações" (FLORES, 2013, p. 9).

Mercado e Araújo (2010), dentro do curso Mídias na Educação, focaram os materiais de estudo, aplicando questionários sobre as reflexões propostas nos fóruns. Como resultado, os autores relatam que “[...] o nível de letramento digital do cursista interfere na dinâmica e na qualidade de sua interação nos fóruns de discussão, de modo que, quanto maior for seu letramento digital, mais relevantes serão suas intervenções" (MERCADO; ARAÚJO, 2010, p. 178).

Três trabalhos propuseram temas relacionados à formação docente em contextos digitais. Silva (2012) fez um estudo teórico destacando que

[...] muitas vezes a formação do professor, no que tange a inserção das NTICs em sua prática, acaba sendo confundida com a ideia de curso de computação, ou seja, 
centra-se na preocupação com o treinamento do professor no uso de hardware e software em suas aulas (SILVA, 2012, p. 2).

Como resposta ao desafio, o autor propõe, no que se refere ao letramento digital para a formação de professores, que há de incluir-se "[...] nos programas de formação o caráter reflexivo crítico para que a inserção das novas tecnologias na prática docente não seja apenas mecânico e reprodutor” (SILVA, 2012, p. 12).

Baptista e Pereira (2015, p. 76) apresentam um estudo de caso que examinou a "[...] relação entre diferentes contextos condicionantes da inserção do letramento digital: o prescritivo e orientativo". As autoras argumentam que:

No universo contemporâneo, em que as TIC possibilitaram a emergência de diversas formas de comunicação e de interação, formar indivíduos competentemente letrados requer das escolas que proporcionem o desenvolvimento de diferentes práticas letradas e que incluam os letramentos múltiplos, entre eles, os digitais, já que estes perpassam praticamente todas as atividades humanas hodiernas (BAPTISTA; PEREIRA, 2015, p. 78).

Como resultado, as pesquisadoras relatam que há,

[...] do ponto de vista do contexto prescritivo e orientativo, uma ruptura entre os documentos do contexto externo e os do interno. Esse fato sugere que as prescrições e orientações oficiais, tanto as da esfera nacional quanto as da estadual, sendo esta última a que a escola-campo de estudo está vinculada, acabam não chegando ao seu destino final, a instituição escolar" (BAPTISTA; PEREIRA, 2015, p. 87).

Moura (2019, p. 128) fez uma revisão sistemática e abordou a problematização das “[...] percepções, apropriações e significações de professores e alunos sobre [...] a inserção das tecnologias digitais da informação e comunicação nos contextos formativos". A autora argumenta que o que se vê hoje é que as TDIC impulsionaram diferentes dimensões da vida em sociedade; entretanto, as escolas não acompanham essa tendência.

\section{Soluções propostas para os desafios apresentados nos problemas e nos argumentos de pesquisa}

Inicialmente, evidenciamos as soluções para os problemas apresentados e considerações sobre os argumentos das pesquisas que apontam para a formação docente, seja a inicial e/ou a continuada com o intuito de preparar os professores para a apropriação das tecnologias e a aquisição de competências relacionadas ao 
letramento digital (FRANCISCO; FERREIRA; GOULART, 2019; LANDGRAFVALERIO, 2012; NERY; COSTA; SOUZA, 2018; OLIVEIRA; SOUZA, 2018; BARBETA; OLIVEIRA; SANTOS, 2017), além de investimento em educação e tecnologia por parte do governo (SILVA JÚNIOR, 2017).

Alguns autores trazem afirmações otimistas sobre o tema, como inovações em sala de aula com a utilização de tecnologias digitais, que têm, como consequência, mudança de hábitos nos professores (OLIVEIRA; MELLO-PAIVA, 2019); uma compreensão dos docentes sobre o papel da tecnologia, que pode também ser aliada e necessária à sua capacitação (SANTOS; CICHELERO, 2012). Outros relatam atividades bem-sucedidas (BEDRAN, 2016; FREITAS, 2010; MERCADO; ARAÚJO, 2010; GOMES, 2016; MEDEIROS; NASCIMENTO, 2014).

Entretanto, vários trabalhos apresentam conclusões mais céticas em relação à adoção das tecnologias na educação e experiências de letramento digital na escola, como, por exemplo, Flores (2013), que encontrou ações de letramento digital influenciadas pelo modelo de educação tradicional, centrado na transmissão de informações; e Machado, Aragão e Lopes (2019), que constataram uma abordagem que pouco contribuiria para uma capacitação de futuros docentes. Resultado semelhante foi encontrado por Barbeta, Oliveira e Santos (2017), em que os docentes tiveram pouca compreensão em relação ao letramento digital. Já Cabral e Mickalski (2018) relataram que professores possuem uma compreensão do letramento digital por uma perspectiva tecnológica. Sobre a escola, Moura (2019) aponta características analógicas, que não privilegiam a evolução dos meios comunicativos digitais da sociedade tecnológica. O uso das tecnologias geralmente é restrito a disciplinas eletivas e atividades extracurriculares, como constatado por Marzari e Leffa (2013); e, como apontado por Alves e Silva (2015), são frequentes atividades baseadas na criação e projeção de slides em sala de aula.

Os resultados encontrados pelos autores dos artigos pesquisados impulsionam-nos a projetar um espectro que tem, em uma das pontas, conclusões sobre experiências mais favoráveis de letramento digital de professores; e, na outra extremidade, experiências menos produtivas. Isso era de se esperar se levarmos em conta as diferenças nas formações iniciais dos professores nas licenciaturas, relativas ao currículo das universidades, infraestrutura tecnológica, conhecimentos, habilidades 
e atitudes voltadas ao uso de tecnologias digitais dos alunos professores-emformação, oportunidades de capacitação e desenvolvimento, dentre outros aspectos.

\section{Considerações finais}

Tivemos como objetivo pesquisar estudos recentes sobre letramento digital na formação de professores. Investigamos publicações recentes fazendo uso do Google Acadêmico como base de dados. Buscamos artigos publicados em periódicos avaliados por pares, disponível para download gratuito, durante o período compreendido entre 2010 e 2019. Utilizamos uma revisão sistemática seguida de análise qualitativa dos dados. Os resultados mostraram um total de 22 artigos, sendo 21 sobre letramento digital e um sobre literacia digital. Não encontramos nenhum trabalho sobre alfabetização dentro dos critérios utilizados.

Os resultados mostraram uma tendência para estudos sobre letramento digital na formação de professores de línguas, sendo a maioria das pesquisas de cunho qualitativo. Encontramos relatos de ações bem-sucedidas, mas também algumas não muito otimistas. As sugestões dos autores dos trabalhos para a superação dos desafios do letramento digital são, principalmente, ações de formação. Assim sendo, com base nos resultados do estudo, propomos sugestões para desenvolver competências de letramento digital de professores em formação.

Além de disciplinas eletivas, os currículos dos programas de formação, principalmente as licenciaturas, deveriam incluir disciplinas obrigatórias com conteúdos relacionados ao desenvolvimento das competências de letramento digital, e, ainda, utilizar as TDIC em outras disciplinas. Além dos cursos teóricos, atividades práticas, de laboratório e de extensão devem ser incluídas no desenvolvimento de letramento digital de professores em formação.

Para os professores em serviço, sugerimos a realização de cursos de educação continuada, além de seminários e workshops, nos quais os professores poderiam, além de assistir palestras, compartilhar experiências de atividades realizadas com seus alunos e, ainda, conhecer trabalhos de colegas, enriquecendo, dessa forma, suas carreiras e contribuindo para o desenvolvimento da cidadania digital dentro da esfera educacional. 
Assim, fechamos o artigo apontando para a necessidade de mais pesquisa sobre o letramento digital pelos docentes, principalmente aqueles que estão nos cursos de formação de professores.

\section{Referências}

ALVES, E. J.; SILVA, B. D. A formação de professores online contribui para a literacia digital docente? Estudo de caso em curso de formação docente online no Brasil. Revista de Estudios e Investigación En Psicología y Educación, Coruña, n. 13, p. 43-48, 2015. DOI: http://dx.doi.org/10.17979/reipe.2015.0.13.305.

ATA, R.; YILDIRIM, K. Exploring Turkish Pre-Service Teachers' Perceptions and Views of Digital Literacy. Education Sciences, v. 9, n. 1, p. 40, 2019. DOI: 10.3390/educsci9010040

BAPTISTA, L. M. T. R.; PEREIRA, E. C. A tecnologia educacional e o letramento digital na escola pública: algum estranho no ninho?. Matraga, Rio de Janeiro, v. 22, n. 36, p. 76-94, 2015. DOI: http://dx.doi.org/10.12957/matraga.2015.17048

BARBETA, C. F.; OLIVEIRA, J. C.; SANTOS, T. S. Letramento digital e redes sociais virtuais: uma pesquisa feita com recém-graduados em Pedagogia. Revista Saberes Universitários, Campinas, v. 2, n. 1, p. 38-49, 2017.

BAWDEN, D. Origins and concepts of digital literacy. Digital literacies: concepts, policies and practices, v. 30, n. 2008, p. 17-32, 2008.

BEDRAN, P. F. Letramento digital e a formação do professor de língua na contemporaneidade. Revista EntreLinguas, Araraquara, v. 2, n. 2, p. 225-248, 2016.

BRINER, R. B.; DENYER, D. Systematic review and evidence synthesis as a practice and scholarship tool. In: BRINER, R. B.; DENYER, D. Oxford Handbook of evidence-based management: Companies, classrooms and research, 2012. p. 112-129.

BUCKINGHAM, D. Defining digital literacy: What do young people need to know about digital media?. Nordic journal of digital literacy, v. 1, p. 21-34, 2006.

BUZATO, M. El Khouri. Cultura digital e apropriação ascendente: apontamentos para uma educação 2.0. Educação em Revista, Belo Horizonte, v. 26, n. 3, p. 283-303, 2010. DOI: http://dx.doi.org/10.1590/S0102-46982010000300014

CABRAL, Z. A.; MICKALSKI, M. A. Olhares acerca do letramento digital: perspectivas da prática. Revista de Ensino, Educaşão e Ciências Humanas, Londrina, v. 19, n. 4, p. 472-477, 2018. DOI: http://dx.doi.org/10.17921/2447-8733.2018v19n4p472-477

COLELLO, S. M. G. Alfabetização ou alfabetização digital. International Studies on Law and Education, São Paulo, v. 23, p. 5-12, maio/ago. 2016.

COMITÊ GESTOR DA INTERNET NO BRASIL (CGI.br). Núcleo de Informação e Coordenação do Ponto BR (NIC.br). Centro Regional de Estudos para o Desenvolvimento da Sociedade da Informação (Cetic.br). Pesquisa sobre o uso das tecnologias da informação e comunicação nos domicílios brasileiros - TIC domicílios 2014. São Paulo: Comitê Gestor da Internet no Brasil, 2015. 
COMITÊ GESTOR DA INTERNET NO BRASIL (CGI.br). Núcleo de Informação e Coordenação do Ponto BR (NIC.br). Centro Regional de Estudos para o Desenvolvimento da Sociedade da Informação (Cetic.br). Pesquisa sobre o uso das tecnologias de informação e comunicação nos domicílios brasileiros: TIC domicílios 2018. São Paulo: Comitê Gestor da Internet no Brasil, 2019.

ESHET-ALKALAI, Y. Digital literacy: A conceptual framework for survival skills in the digital era. Journal of educational multimedia and hypermedia, v. 13, n. 1, p. 93-106, 2004.

FLORES, J. B. Letramento digital: um olhar para a formação continuada de professores que atuam no UCA. Educação \& Tecnologia, Belo Horizonte, v. 18, n. 1, p. 9-17, 2013.

FRANCISCO, E.; FERREIRA, H. M.; GOULART, I. C. V. Letramento digital: do uso das tecnologias digitais à formação dos professores de língua portuguesa, o que se discute sobre isso?. Texto Livre: Linguagem e Tecnologia, Belo Horizonte, v. 12, n. 3, p. 109-127, 2019. DOI: https://doi.org/10.17851/1983-3652.12.3.\%25p

FREITAS, M. T. Letramento digital e formação de professores. Educação em Revista, Belo Horizonte, v. 26, p. 335-352, 2010. DOI: https://doi.org/10.1590/S010246982010000300017

GILSTER, P. Digital literacy. New York: Wiley, 1997.

GOMES, S. S. Letramento digital na formação inicial de professores: a visão de graduandos de pedagogia EaD. Educação, Santa Maria, v. 41, n. 3, p. 579-592, 2016. DOI: http://dx.doi.org/10.5902/1984644415941

GOUGH, D. Weight of evidence: a framework for the appraisal of the quality and relevance of evidence. Research papers in education, v. 22, n. 2, p. 213-228, 2007.

GOUGH, D.; THOMAS, J.; OLIVER, S. Clarifying differences between review designs and methods. Systematic reviews, v. 1, n. 1, p. 28, 2012.

GRANT, M. J.; BOOTH, A. A typology of reviews: an analysis of 14 review types and associated methodologies. Health Information \& Libraries Journal, v. 26, n. 2, p. 91-108, 2009.

KITCHENHAM, B. Procedures for performing systematic reviews. Keele, v. 33, n. 2004, p. 1-26, 2004.

LANDGRAF-VALERIO, C. L. Letramento digital: o blog como estratégia de formação de professores. Revista Tecnologias na Educação [online], v. 4, n. 7, p. 1-11, 2012.

LANKSHEAR, C.; KNOBEL, M. Digital literacy and digital literacies: Policy, pedagogy and research considerations for education. Nordic Journal of digital literacy, v. 1, n. 1, p. 12-24, 2006.

MACHADO, C. M.; ARAGÃO, C. O.; LOPES, P. H. M. O letramento digital na formação de professores a distância. Caderno Seminal, Rio de Janeiro, v. 33, n. 33, p. 49-81, 2019. DOI: https://doi.org/10.12957/cadsem.2019.40963

MARZARI, G. Q.; LEFFA, V. J. O letramento digital no processo de formação de professores de línguas. Tear: Revista de Educação, Ciência e Tecnologia, Canoas, v. 2, n. 2, p. 1-18, 2013. 
MEDEIROS, Z.; NASCIMENTO, S. S. Letramento digital na formação inicial de professores em um curso a distância. Educação, Formação \& Tecnologias, Monte da Caparica, v. 7, n. 2, p. 74-93, 2014.

MERCADO, L. P.; ARAÚJO, R. S. Letramento digital nas interações on-line: análise dos fóruns de discussão do programa de formação continuada em mídias na educação. Revista Brasileira de Estudos Pedagógicos, Brasília, v. 91, n. 227, p. 178-232, 2010. DOI: http://dx.doi.org/10.24109/2176-6681.rbep.91i227.609

MOURA, K. M. P. Revisão sistemática sobre letramento digital na formação de professores. Texto Livre: Linguagem e Tecnologia, Belo Horizonte, v. 12, n. 3, p. 128-143, 5 set. 2019. DOI: http://dx.doi.org/10.17851/1983-3652.12.3.128-143

NERY, S. C.; COSTA, S. R.; SOUZA, M. S. Letramento digital: os desafios da relação discente-docente. Reves - Revista Relações Sociais, Viçosa, v. 1, n. 3, p. 397-406, 2018. DOI: http://dx.doi.org/10.18540/revesvl1 iss3pp0397-0406

OLIVEIRA, C. S.; SOUZA, A. C. R. O letramento digital na formação inicial e continuada de professores. Revista Igapó, Manaus, v. 12, n. 2, p. 130-140, 2018.

OLIVEIRA, E. C.; MELLO-PAIVA, K. S. F. Letramento digital em um curso de formação continuada de professores de língua inglesa. Leitura, Maceió, v. 1, n. 53, p. 105-128, 2019. DOI: http://www.dx.doi.org/10.28998/2317-9945.2014v1n53p81-103

OLIVEIRA, M. M.; GIACOMAZZO, G. F. Educação e cidadania: perspectivas da literacia digital crítica. EccoS Revista Científica, São Paulo, n. 43, p. 153-174, 2017. DOI: https://doi.org/10.5585/eccos.n43.7393

PEREIRA, E. G. Alfabetização e letramento digital: formação contínua para professores apoiada pela interoperabilidade didática. Colóquio Luso-Brasileiro de Educaşão-COLBEDUCA, v. 1, p. 472-484, 2016.

RAMOS, A.; FARIA, P. Literacia digital e literacia informacional: breve análise dos conceitos a partir de uma revisão sistemática de literatura. Revista Linhas, Florianópolis, v. 13, n. 2, p. 29-50, 2012.

SANTOS, L. I. S.; CICHELERO, M. Inclusão do letramento digital na formação continuada de docentes de língua inglesa: algumas contribuições. Polifonia, Cuiabá, v. 19, n. 25, p. $197-$ 222, 2012.

SAUR-AMARAL, I. Towards a methodology for literature reviews in social sciences. Investigaçao e Intervençâo em Recursos Humanos, n. e, p. 1-10, 2011. DOI: https://doi.org/10.26537/iirh.v0i3.1875

SILVA, S. P. Letramento digital e formação de professores na era da web 2.0: o que, como e por que ensinar. Hipertextus Revista Digital, n. 8, p. 1-13, 2012.

SILVA, W. R..; REIS, N. V. Construção de práticas de letramento digital na formação inicial do professor de língua materna. Interfaces da Educação, Paranaíba, v. 8, n. 24, p. 97-118, 2017. DOI: https://doi.org/10.26514/inter.v8i24.1373

SILVA JÚNIOR, S. N. A identidade e a formação do professor de português: questões de linguagem, percepção de ensino e letramento digital. Linguagens - Revista de Letras, Artes e 
Comunicação, Blumenau, v. 11, n. 1, p. 340-356, 2017. DOI: http://dx.doi.org/10.7867/19819943.2017v11n1p340-356

SOARES, M. Novas práticas de leitura e escrita: letramento na cibercultura. Educação \& Sociedade, Campinas, v. 23, n. 81, p. 143-160, 2002.

THOMPSON, K. Digital Literacy and the ICT Curriculum. BU Journal of Graduate Studies in Education, v. 8, n. 1, p. 10-13, 2016.

TRANFIELD, D.; MOUCHEL, D. D. Developing an evidence-based approach to management knowledge using systematic review. In: European Academy of Management EURAM, 2002, Stockholm. Anais... Stockholm: Advanced Management Research Centre, Cranfield School of Management, 2002. Disponível em: https://www.semanticscholar.org/paper/Developing-an-evidence-based-approach-tomanagement-Tranfield-Denyer/bdb9b75e90303809665be4410822e0b9b0e8ccb2. Acesso em: 20 fev. 2020.

UNESCO. Organização das Nações Unidas para a Educação, a Ciência e a Cultura. Digital literacy and basic competences from the teacher's and learner's perspectives. 2011. Disponível em: https://unesdoc.unesco.org/ark:/48223/pf0000214485. Acesso em: 10 fev. 2020.

RECEBIDO: $15 / 05 / 2020$

APROVADO: 04/12/2020
RECEIVED: 05/15/2020

APPROVED: $12 / 04 / 2020$
RECIBIDO: $15 / 05 / 2020$

APROBADO: 04/12/2020 